\title{
Knowledge, attitude and practice of self medication among undergraduate medical students in a teaching institution
}

\author{
Anbarasi Sundararajan*, Ashok Kumar Thangappan
}

Department of Pharmacology, Kanyakumari Government Medical College Hospital, Asaripallam, Kanyakumari, Tamilnadu, India

Received: 03 October 2018 Accepted: 26 October 2018

*Correspondence to:

Dr. Anbarasi Sundararajan, Email: anbarasi1412@yahoo.in

Copyright: (C) the author(s), publisher and licensee Medip Academy. This is an openaccess article distributed under the terms of the Creative Commons Attribution NonCommercial License, which permits unrestricted noncommercial use, distribution, and reproduction in any medium, provided the original work is properly cited.

\begin{abstract}
Background: Self medication is the usage of medicines without the advice of the physicians, without proper diagnosis of the illnesses and without any prescription. Medical students are more liable to self medicate themselves due to their partial knowledge and easy availability of drugs. This study was conducted to assess the pattern of self medication in undergraduate medical students. This study was conducted to assess the knowledge, attitude and practice of self medication among undergraduate medical students in Kanyakumari government medical college, a teaching institute in South Tamilnadu.

Methods: A self-designed questionnaire was given to the undergraduate medical students who were willing to participate in the study. 264 students participated of which 111 were males and 153 were females in the age group of 17-24 yrs. Data were collected. Results were given as percentages and counts.

Results: The prevalence of self medication was found to be $85.2 \%$ which is very high. Commonest reason was its usefulness in mild illnesses $(89.3 \%)$. The commonly used group of drugs was antipyretics (98.6\%), ointments (44.4\%) and antibiotics $(41.3 \%)$. The commonest source of information was old prescriptions $(62.8 \%)$. The common ailments were fever (88\%) and cough and cold $(80.4 \%)$. Ironically $72.88 \%$ opined that self medication should not be practiced.

Conclusions: Increased prevalence of self medication among medical students implies that they are highly exposed to the adverse effects of drugs. Steps should be taken to curtail self medication among medical students by educating and creating awareness among them.
\end{abstract}

Keywords: Medical students, Over the counter drugs, Questionnaire, Self medication

\section{INTRODUCTION}

Self-medication involves the use of medicinal products by the individuals to treat self-recognized disorders or symptoms, or the intermittent or continuous use of a medication prescribed by a physician for chronic or recurring diseases or symptoms. ${ }^{1}$ Self medication differs from self care in that it involves drugs that may do good or cause harm. ${ }^{2}$ Self-medication is widely practiced worldwide and often considered as a component of selfcare. $^{3}$ It is a behavioral response of the human beings in which an individual uses drugs to treat self diagnosed minor symptoms or disorders having the potential to do good as well as harm. It involves use of both allopathic and non allopathic drugs. It is widely practiced both in the rural and urban population. Particularly in a developing country like India many drugs are dispensed over the counter without prescription. It provides a low-cost alternative for the people. It helps to overcome or treat minor illnesses.

The practice of self medication must be based on authentic medical information to avoid irrational use of drugs which in turn can cause wastage of resources, increased 
resistance of pathogens to drugs and can lead to serious health hazards like prolonged sufferings, drug reaction and drug dependence. The WHO has also pointed out that responsible self-medication can help prevent and treat ailments that do not require medical consultation and provides a cheaper alternative for treating common illness. Moreover, antimicrobial resistance is a current problem worldwide particularly in developing countries like India where antibiotics are often available over the counter without a prescription. ${ }^{4}$

Being future medical practitioners, self medication has a special impact in medical students. Even in the general population the availability of various sources of information like internet, google search has led to the increased knowledge about the diseases and drugs and hence self medication. Medical students are more likely to take self medication since they have easy access to information from drug indices, literature, and other medical students to self-diagnose and self-medicate. In addition, they have easy access to the medication itself.

This study was conducted to assess the knowledge, attitude and practice of self medication among undergraduate medical students in Kanyakumari Government Medical College and Hospital, Asaripallam in Tamilnadu State.

\section{METHODS}

This was a cross-sectional, questionnaire-based study. The study was done during the period June 2018- August 2018 (3 months). This study was conducted in undergraduate medical students from Kanyakumari Government medical college, a tertiary care district medical college and hospital in Tamilnadu. A self designed questionnaire was given to the undergraduate medical students who were willing to participate in the study.

All the undergraduate medical students who were willing to participate in the study were included. Students who were not willing were excluded. Also, the incompletely filled up questionnaires were excluded. Prior permission was obtained from the ethics committee of the institution for conducting the study. The purpose of the study was explained to the participating students and confidentiality was ensured. Written informed consent was obtained from every student before filling the questionnaire.

The questionnaire consisted of closed ended questions regarding the usage of self medication during the past one year, reason for preferring it, conditions for which the students have self medicated, the group of drugs they have used, source of information regarding the drugs, whether they were aware of the adverse effects of the drugs they had used or not, completion of the full course of the medication and their opinion regarding self medication. The study was conducted among 290 students who were willing to participate. Of this 268 students only completed the questionnaire. Of these 7 students had regular intake of medications and hence were excluded. The number of participants fulfilling the criteria was 261 students.

\section{Statistical analysis}

All the data were collected. Data was analysed by the Microsoft Excel software. The results were given as percentages and counts. The total values did not add up to $100 \%$ as there were multiple responses for a single question.

\section{RESULTS}

This study was conducted among 264 students of which $111(42.05 \%)$ were males and $153(57.95 \%)$ were females. The students were in the age group of 17 to 24 years. Among these 264 students, 53 (20.1\%), 67 (25.4\%), 83 $(31.4 \%), 61(23.1 \%)$ were studying in I MBBS, II MBBS, III-I MBBS, and III-II MBBS, respectively.

Authors observed that $225(85.2 \%)$ students practiced SM in the preceding one year with 117 (52\%) female participants outnumbering male participants 108 (48\%). The most common reason for self medication was that it was useful for mild illnesses $(89.3 \%)$. This was followed by reasons like easy availability and convenience $(76 \%)$, time saving (59\%), economical (46.6\%) and feeling of self confidence $(32.4 \%)$ (Figure 1$)$.

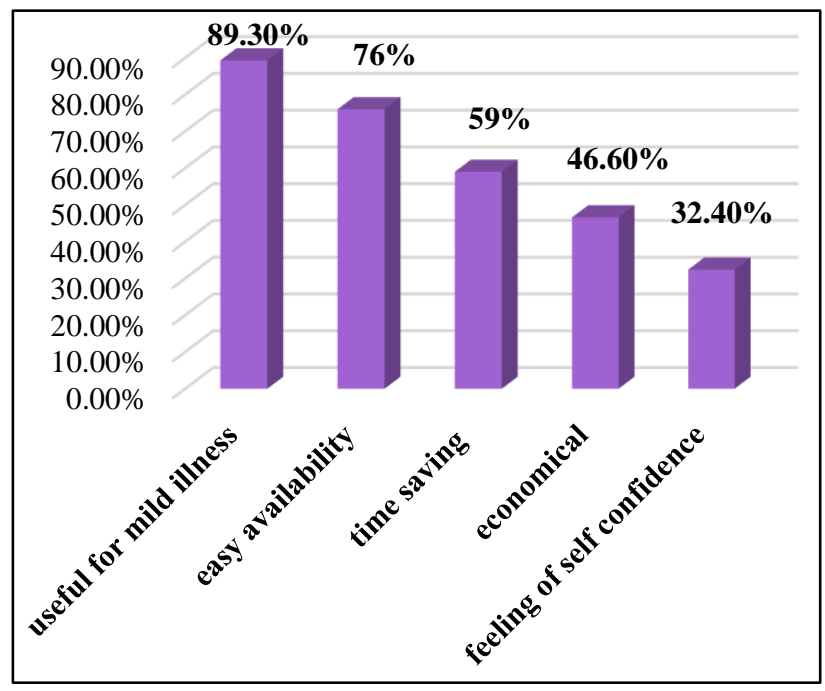

Figure 1: Reasons for using self medication.

As shown in Figure 2, fever $198(88 \%)$ and cough and cold $181(80.4 \%)$ were the most frequently reported illnesses followed by headache $169(75.1 \%)$ diarrhea $76(33.7 \%)$ and vomiting $63(28 \%)$ for which self medication was practiced. The commonly used drugs were antipyretics 222 (98.6\%), ointments 100 (44.4\%), antibiotics 93 (41.3\%), antacids $90(40 \%)$ and analgesics $89(39.5 \%)$ as shown in Figure 3.

The commonest source of information about the drugs was through old prescriptions $166(62.8 \%)$, followed by advice 
from parents, advice from doctor without prescription, advice from friends, advice from pharmacist and reading material which were 126 (47.7\%), $106 \quad(40.1 \%)$, $100(37.8 \%), 87(32.9 \%)$ and $83(31.4 \%)$ respectively (Figure 4).

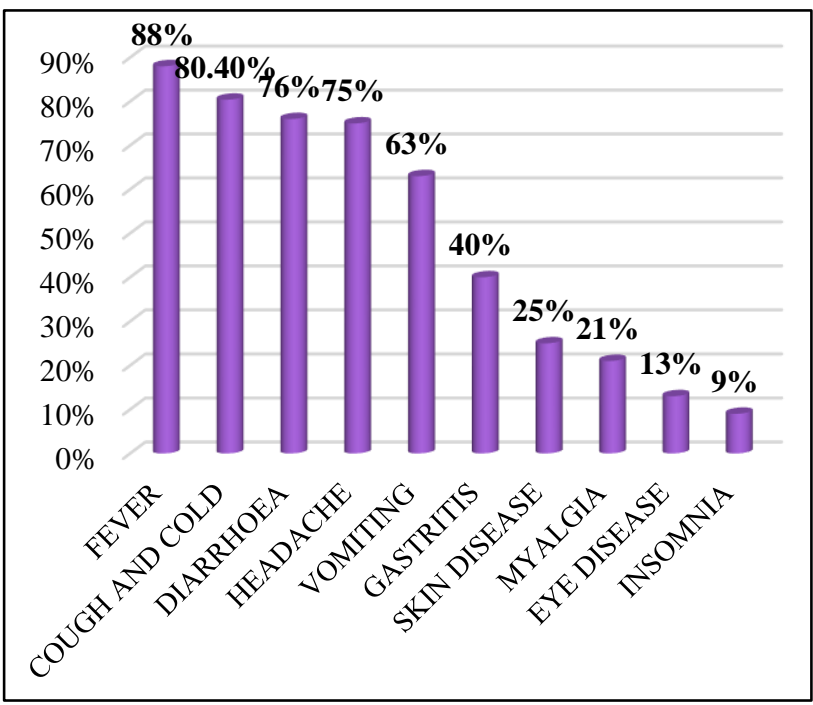

Figure 2: Common illnesses for which self medication is used.

The twenty five $(11.11 \%)$ students were aware of the side effects for all the drugs, $141(62.66 \%)$ were aware of the side effects only for some drugs and $47(20.88 \%)$ students were not much aware of the adverse effects for any of the drugs (Table 1).

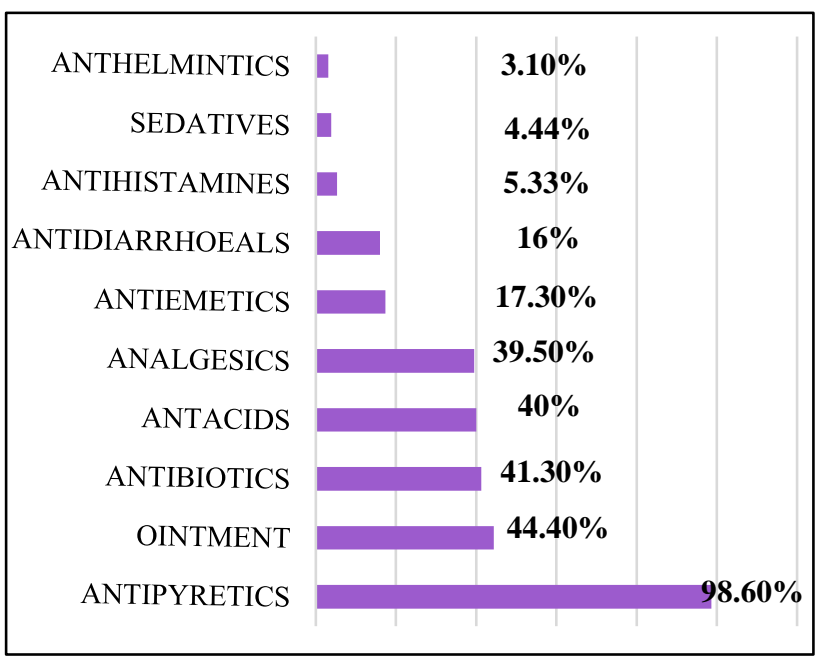

Figure 3: Groups of drugs used in self medication.

Authors also found out that only 8 students took full course of medications for all the drugs, 95 students took the full course only for some drugs and 120 students did not take full course for any of the drugs. Also $52(23.1 \%)$ students gave the opinion that self medication can be practiced whereas $164(72.88 \%)$ students opined that self medication should not be practiced (Figure 5).

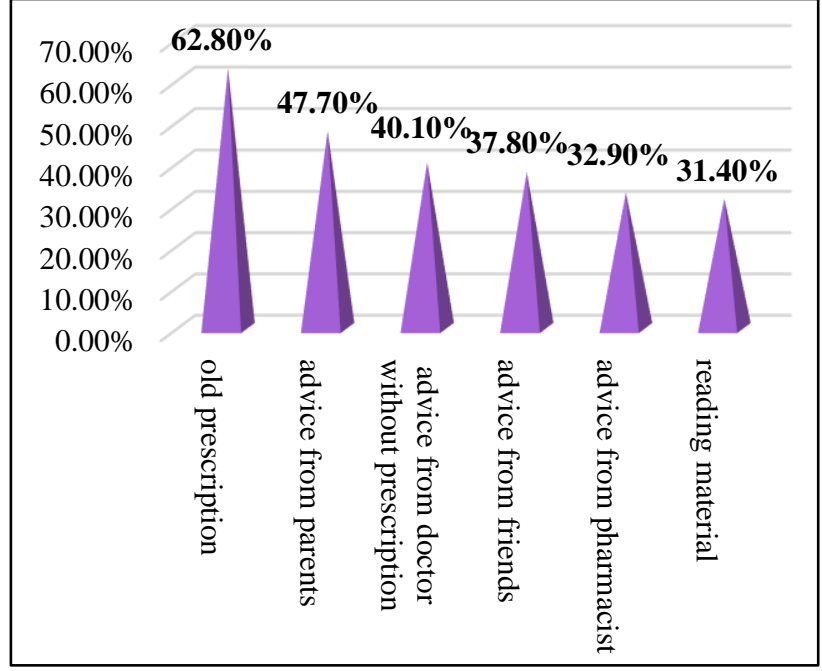

Figure 4: Source of information about the drugs.

Table 1: Awareness about the adverse effects of drugs.

\begin{tabular}{|ll|}
\hline Category & $\%$ of students \\
\hline $\begin{array}{l}\text { Aware of dose and ADR of all } \\
\text { drugs }\end{array}$ & $11.11 \%$ \\
\hline $\begin{array}{l}\text { Aware of dose and ADR of some } \\
\text { drugs only }\end{array}$ & $62.66 \%$ \\
\hline Not much aware & $20.88 \%$ \\
\hline
\end{tabular}

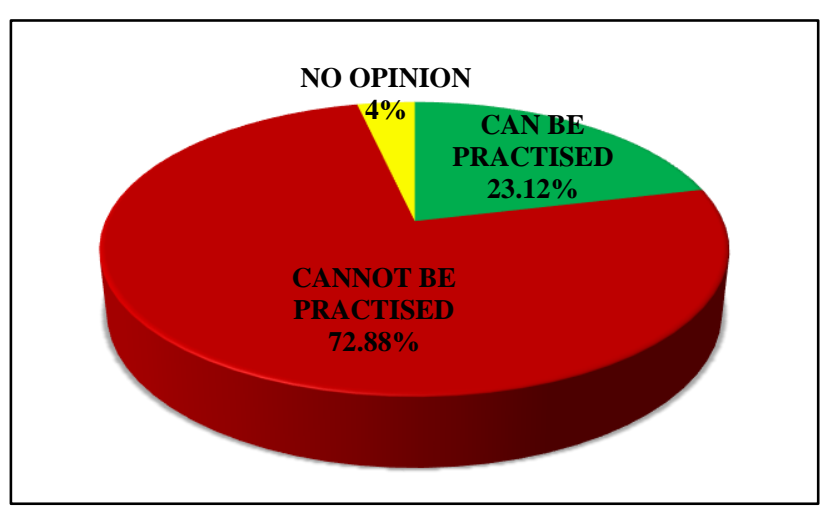

Figure 5: View of students regarding self medication.

\section{DISCUSSION}

According to WHO, self-medication is defined as "the selection and use of medicines by individuals to treat selfrecognized illnesses or symptoms".

It involves obtaining medications without a prescription, taking medicines on the advice of pharmacists, relative or friends without consulting medical professional, sharing medicines with family members /friends or consuming leftover medicines stored at home. ${ }^{5}$ People are not only using non-prescription drugs but also prescription drugs, as self-medication products, without supervision. ${ }^{2}$

In present study authors observed that $85.2 \%$ of the students practiced self medication. But many other studies 
have given varied prevalence ranging from 43.2 to $91 \% .^{6-11}$ This may be due to the varied demography, socioeconomic status and the availability of nonprescription drugs over the counter. In our study we have observed that the female students have increased prevalence when compared to the male students. This may be attributed to their menstrual related problems and the use of analgesics. Some other studies also have shown that female outnumbers males. ${ }^{12,13}$

Most common reason for using the self medication has been found out to be usefulness in mild illnesses and easy availability. This finding goes in accordance with the observations of some other studies. ${ }^{8,14,15}$ conducted in India. The common ailments for which self medications were used are fever, cough and cold and headache. The same were reported in a study conducted in Ethiopia. ${ }^{6}$ One study conducted in South India has reported cough and cold to be the commonest cause. ${ }^{10}$

In accordance with the common ailments our study shows antipyretics to be the commonly used medications, followed by the use of local ointments and antibiotics. In our study use of antibiotics is found to be $41.3 \%$. One study which was carried out in West Bengal has reported antibiotics to be the most commonly used drugs. ${ }^{14}$ Another study done in Karachi also has shown increased use of antibiotics. ${ }^{11}$ This indicates that the use of antibiotics as self medication is increasing. This warrants the proper implementation of regulatory control of over the counter drugs.

Regarding the source of information about the drugs our study revealed that old prescriptions from a registered medical practitioner to be the leading source. This was followed by the advice from the parents, advice from the doctor without prescription. This is in contrast with the other studies which have revealed reading material to be the leading cause followed by old prescription. ${ }^{16,17}$ The students who were clearly aware of the adverse effects of all the drugs are only $11.1 \%$. Those who were aware of the adverse effects of some of the drugs only are $62.66 \%$. Awareness is poor among $20.88 \%$ of the students. In spite of all these results, $72.88 \%$ have opined that self medication should not be practiced. This is similar to attitude of the students in the study conducted in Bahrain. ${ }^{18}$

\section{CONCLUSION}

The study shows that self medication is being practiced highly by the medical students who are equally exposed to the hazards of self medication like the general population. Self medication should be opted for only in appropriate situations and not inadvertently. Education of the medical students for safe self medication practices is the need of the hour. Awareness about the various adverse effects of the drugs, danger of interactions and antibiotic resistance should be created even among medical students. This will ensure safer self medication practices among the medical students. They will spread the awareness which in turn will benefit the society.

\section{ACKNOWLEDGEMENTS}

Authors would like to thank the undergraduate medical students of Kanyakumari Government Medical College students who willingly participated in the study and completed the questionnaire.

Funding: No funding sources Conflict of interest: None declared

Ethical approval: The study was approved by the Institutional Ethics Committee

\section{REFERENCES}

1. WHO. Guidelines for the regulatory assessment of medicinal products for use in Self-medication. 2000. Available

at: http://apps.who.int/medicinedocs/pdf/S2218e/s2218e. pdf.

2. Hussain S, Malik F, Hameed A, Ahmad S, Riaz H. Exploring health seeking behavior, medicine use and self medication in urban and rural Pakistan. Southern Med Review. 2010 Oct 1;3(2):32-5.

3. Hughes CM, McElnay JC, Fleming GF. Benefits and risks of self medication. Drug Safety. 2001 Dec 1;24(14):1027-37.

4. Pagan JA, Ross S, Yau J, Polsky D. Self-medication and health insurance coverage in Mexico. Health Policy. 2006 Jan 1;75(2):170-7.

5. World Health Organization Role of pharmacists in self-care and self-medication Available at: http://apps.who.int/medicinedocs/pdf/whozip32e/who zip32e.pdf.

6. Abay SM, Amelo W. Assessment of self-medication practices among medical, pharmacy, and health science students in Gondar University, Ethiopia. J Young Pharmacists. JYP. 2010 Jul;2(3):306.

7. Gutema GB, Gadisa DA, Kidanemariam ZA, Berhe DF, Berhe AH, Hadera MG, et al. Self-medication practices among health sciences students: the case of Mekelle University. J Applied Pharmaceutical Sci. 2011 Dec 1;1(10):183-9.

8. Girish HO, Divya HM, Prabhakaran S, Venugopalan PP, Koppad R, Acharya A. A cross-sectional study on self medication pattern among medical students at Kannur, North Kerala. J Evol Med Dent Sci. 2013 Nov 11;2:8693-700.

9. Patel P, Prajapati A, Ganguly B, Gajjar B. Study on impact of pharmacology teaching on knowledge, attitude and practice on self-medication among medical students. Int J Med Sci Public Health. 2013 Apr 1;2(2):181-7.

10. Kumar N, Kanchan T, Unnikrishnan B, Rekha T, Mithra P, Kulkarni V, et al. Perceptions and practices of self-medication among medical students in coastal South India. PloS One. 2013 Aug 28;8(8):e72247. 
11. Zafar SN, Syed R, Waqar S, Zubairi AJ, Vaqar T, Shaikh M, Yousaf W, Shahid S, Saleem S. Selfmedication amongst university students of Karachi: prevalence, knowledge and attitudes. J Pakistan Med Assoc. 2008;58(4):214-7.

12. Klemenc-Ketis Z1, Hladnik Z, Kersnik J. A cross sectional study of sex differences in self-medication practices among university students in Slovenia. Coll Antropol. 2011 Jun;35(2):329-34.

13. James H, Handu SS, Al Khaja KA, Otoom S, Sequeira RP. Evaluation of the knowledge, attitude and practice of self-medication among first-year medical students. Med Principles Practice. 2006;15(4):270-5.

14. Banerjee I, Bhadury T. Self-medication practice among undergraduate medical students in a tertiary care medical college, West Bengal. J Postgraduate Med. 2012 Apr 1;58(2):127.

15. Badiger S, Kundapur R, Jain A, Kumar A, Pattanshetty S, Thakolkaran N, et al. Self-medication patterns among medical students in South India. Australasian Med Jurnal. 2012;5(4):217.
16. Klemenc-Ketis Z, Hladnik Z, Kersnik J. Selfmedication among healthcare and non-healthcare students at University of Ljubljana, Slovenia. Med Principles Practice. 2010;19(5):395-401.

17. Sontakke SD, Bajait CS, Pimpalkhute SA, Jaiswal KM, Jaiswal SR. Comparative study of evaluation of self-medication practices in first and third year medical students. Int J Biol Med Res. 2011 Apr 30;2(2):561-4.

18. Gaikwad NR, Patil AB, Khan TA. Comparative evaluation of knowledge, attitude and practice of selfmedication among first and second year medical students. J Datta Meghe Inst Med Sci Univ. 2010;5:157-62.

Cite this article as: Sundararajan A, Thangappan AK. Knowledge, attitude and practice of self medication among undergraduate medical students in a teaching institution. Int $\mathrm{J}$ Basic Clin Pharmacol 2018;7:2414-8. 